\title{
O Instituto Geofísico da Universidade do Porto no contexto da Guerra Fria (1960-1963)
}

\author{
Inês Monteiro \\ inesfilipasm@gmail.com
}

\section{Resumo}

Este artigo visa explorar o papel do Instituto Geofísico da Universidade do Porto (IGUP) no contexto da Guerra Fria, entre os anos de 1960 e 1963. Através da análise dos documentos do arquivo do IGUP, pretende-se entender a sua participação na rede científica internacional World-Wide Standard Seismograph Network (WWSSN), um programa criado pelo núcleo governamental norte-americano U. S. Department of Commerce Coast and Geodetic Survey (C\&GS), nas duas primeiras décadas da segunda metade do século XX, projectado de forma a obter medições sismológicas calibradas e estandardizadas a um nível global, e uma colecção de dados, subsequentemente disponibilizados para investigação científica não classificada. Dada a relevância que este programa teve para a área científica da sismologia, esta investigação foi uma tentativa de perceber como se desenvolveu o projecto ao longo do tempo, e quais os moldes do seu estabelecimento, funcionamento, bem como o impacte directo para o próprio IGUP, para a Universidade do Porto, para a ciência nacional e internacional e para o contexto em que se inseria Portugal na Guerra Fria.

Palavras-chave: IGUP, Instituto Geofísico da Universidade do Porto, Guerra Fria, Sismologia, WWSSN, WorldWide Standard Seismograph Network, U. S. Department of Commerce Coast and Geodetic Survey, Universidade do Porto, Ciência, Estado Novo.

\begin{abstract}
This article aims to explore the role of the Geophysical Institute of the University of Porto (IGUP) in the context of the Cold War, between the years of 1960 and 1963. Through the analysis of the documents that are part of the IGUP archive, I intend to understand its participation in the network International Scientific World-Wide Standard Seismograph Network (WWSSN), a program created by the North-American governmental cell, the US Department of Commerce Coast and Geodetic Survey (C\&GS), in the first two decades of the second half of the 20th century, designed to obtain measurements seismological calibrated and standardized at a global level, and a collection of data, subsequently made available for unclassified scientific research. Given the relevance that this program had for the scientific area of seismology, this investigation was an attempt to understand how the project developed over time, and what were the forms of its establishment, operation, as well as its direct impact for IGUP itself, for the University of Porto, for national and international science and for the context in which Portugal was inserted in the Cold War.
\end{abstract}

Keywords: IGUP, Geophysical Institute of the University of Porto, Cold War, Seismology, WWSSN, WorldWide Standard Seismograph Network, U. S. Department of Commerce Coast and Geodetic Survey, University of Porto, Science, Estado Novo. 


\section{Abreviaturas}

C\&GS - U. S. Department of Commerce Coast and Geodetic Survey

EUA - Estados Unidos da América

IGUP - Instituto Geofísico da Universidade do Porto

NATO - The North-Atlantic Treaty Organization (Organização do Tratado do Atlântico Norte)

URSS - União das Repúblicas Socialistas Soviéticas/ União Soviética

WWSSN - Word-Wide Standard Seismograph Network

\section{Introdução}

O presente artigo visa explorar o papel do Instituto Geofísico da Universidade do Porto (IGUP) no contexto da Guerra Fria, entre os anos de 1960 e 1963. Após um estágio extracurricular no arquivo do dito Instituto durante o mês de Julho de 2019, o contacto com fontes históricas relativas ao enquadramento da tensão ideológica que pautou a segunda metade do século XX revelou-se como um excelente ponto de partida para uma investigação mais profícua da história da instituição no período elencado.

A trajectória deste organismo é muito rica, desde logo a partir da sua inauguração, em 1885. Sob tutela da Faculdade de Ciências da Universidade do Porto, dependendo desta tanto para suporte financeiro como para orientação científica, o Instituto tem passado algo despercebido à historiografia local e nacional, o que faz com que aquilo até hoje publicado sobre a sua história se cinja praticamente a textos de técnicos que por lá foram passando no exercício da sua actividade profissional, e se apaixonaram pela divulgação da vida do observatório de forma mais ou menos amadora. $\mathrm{O}$ trabalho de historiador pouco ou nada aqui se deteve, conquanto não necessariamente devido a escassez de matéria-prima.

O Instituto, que ao longo do tempo foi perdendo muita da sua documentação por razões em parte desconhecidas, preserva ainda um conjunto de documentos referentes àquele que será um dos momentos mais importantes da sua existência até hoje, a sua participação na rede científica internacional World-Wide Standard Seismograph Network (WWSSN), programa criado pelo núcleo governamental americano U. S. Department of Commerce Coast and Geodetic Survey (C\&GS), nas duas primeiras décadas da segunda metade do século XX, projectado de forma a obter medições sismológicas calibradas e estandardizadas a um nível global, e uma colecção de dados, subsequentemente disponibilizados para investigação científica não classificada. Dada a relevância que este programa teve para a área científica da sismologia, esta investigação foi uma tentativa de, a partir do estudo da documentação coeva 
que se encontra no arquivo do IGUP, perceber como se desenvolveu o projecto ao longo do tempo, e quais os moldes dos seus estabelecimento e funcionamento, bem como as consequências directas para o próprio IGUP, para a Universidade do Porto, para a ciência nacional e internacional e para o contexto em que se inseria Portugal na Guerra Fria.

Quanto ao mais, é sobretudo fundamental salvaguardar que o programa desenvolvido no âmbito da rede WWSSN, quer a nível da sua escala, como dos seus objectivos gerais e impactos na história da ciência, elevou as estações participantes a um patamar de contribuição para o progresso científico que a investigação não deve, nem pode ignorar, até porque o acervo arquivístico do Instituto Geofísico da Universidade do Porto permite conhecer profusos aspectos sobre a realidade em causa.

Dessarte, no arquivo do IGUP, encontram-se variados documentos cuja natureza é sobretudo epistolar. É parte do corpo documental correspondência, num total de 58 cartas, tanto expedida como recebida, notas manuscritas do director do IGUP, acerca de conversas e eventos relacionados com a estação sismológica, uma news release enviada pelo U. S. Department of Commerce, Coast and Geodetic Survey, planos da construção da estação e planta da mesma, e ainda uma planta do próprio IGUP. Trata-se, portanto, de um corpo documental com extensão suficiente para que tenha sido possível obter algumas respostas à problemática que se estabeleceu, sobretudo para os anos de 1961 e 1962, em que o efectivo de cartas emitidas e recebidas é maior: 15 em 1961 e 29 em 1962 (44 das 58 cartas).

A correspondência encontra-se quase exclusivamente dactilografada, tendo, na maioria dos casos, uma a duas páginas de extensão. Dependendo do destinatário, o teor das cartas é bastante variado, indo desde os acordos feitos entre o IGUP e o U. S. Department of Commerce Coast and Geodetic Survey, ao planeamento da construção e análise do espaço e condições para tal empresa, passando pelos acordos alfandegários para envio dos instrumentos e material necessários ao desenvolvimento do programa. Constam ainda da documentação discussões orçamentais e referentes a recursos humanos com a reitoria da Universidade e o director da Faculdade de Ciências, o estabelecimento de concursos para a empreitada e convites para a inauguração da estação sismológica. Como todas as cartas em análise são documentos oficiais, com sujeição a carimbo e assinatura dos detentores dos mais altos cargos das entidades envolvidas, assume-se que a fidedignidade aos acontecimentos reais é tanta quanto a possível reunir numa investigação desta natureza.

A principal debilidade destas fontes é a sua "selecção" e sobrevivência ao tempo, uma vez que não chegaram aos nossos dias todas as cartas trocadas no âmbito da inserção do IGUP na rede. A partir destes documentos, tentou-se compreender questões levantadas previamente, 
como quais as características do IGUP que o tornaram adequado às intenções do programa. É verdade que Jon Peterson e Charles R. Hutt, no seu relatório intitulado World-Wide Standardized Seismograph Network: A Data Users Guide, esclarecem critérios de selecção dos lugares em que se desenrolaria o programa, sublinhando importantes cuidados a ter em conta quanto à vida do local em que se encontrassem as estações.

\begin{abstract}
The location of the seismometer vault had much to do with the noise that was observed on the short-period seismograms. Where possible, the vault was isolated from cultural activities (such as cities, roads, railroads, and dams) that are known to generate short-period noise. Nevertheless, there were few high magnification stations in the network that did not show some evidence of cultural noise during daytime hours. ${ }^{1}$
\end{abstract}

Sem embargo, ainda que tal elucide a vantagem da localização do IGUP, não é uma resposta totalmente satisfatória para sua preferência sobre outros lugares, uma vez que qualquer instituto que se dedique a ciências geofísicas deve, em princípio, observar no seu espaço de actuação a mesma ausência de perturbação exterior a que às estações da WWSSN era requerida. Nesta senda, foi então primacial entender como se deu a entrada do IGUP na rede, inquirição que se afigurou extensível também a outras colaborações que o IGUP efectuou no século XX.

Carlos Coutinho Braga, director do IGUP no intervalo cronológico em análise, elaborou um pequeno estudo muito importante que em diversas matérias esclarece as função e missões do organismo ao longo do seu funcionamento, intitulado Instituto Geofísico: Esboço Histórico. Neste, faz saber que "O Instituto colabora deste serviço com diversas entidades nacionais e estrangeiras, designadamente, o "U.S. Coast and Geodetic Survey", "International Seismological Research Center de Edinburgo", "Bureau Central International Seismologique de Strasburgo", etc." ${ }^{\prime 2}$, enviando semanalmente a várias entidades interessadas análises preliminares dos sismos que o instituto registava. Já as análises definitivas eram "compiladas anualmente na publicação "Boletim Sísmico" que é distribuída gratuitamente a algumas centenas de entidades nacionais e estrangeiras interessadas"3. Daqui emanam duas interpretações: 1) o IGUP tinha uma enorme fama dentro da sua área de actividade, sendo "recrutado" para os mais diversos projectos nacionais e internacionais, o que muito deveria alegrar os seus técnicos e investigadores; 2) o IGUP tinha uma grande dependência em relação a outras instituições e isso poderá ter significado a perda de alguma autonomia financeira e científica. Tal visão maniqueísta é algo simplista dentro do que pode ser a miríade de reacções humanas em relação a um determinado assunto, mas não deixa

\footnotetext{
${ }^{1}$ PETERSON, Jon; HUTT, C. R. - World-Wide Standardized Seismograph Network: A Data Users Guide. Virgínia, Estados Unidos da América: United States Geological Survey, 2014, Open-File Report 2014-1218, p. 14.

${ }^{2}$ BRAGA, Carlos Coutinho - Instituto Geofísico: Esboço Histórico. Porto: Faculdade de Ciências da Universidade do Porto, 1969, p. 338.

${ }^{3}$ Idem, ibidem.
} 
de conter em si o gatilho para uma certa curiosidade quanto à reacção do director do IGUP ao convite.

Independentemente deste factor, é inequívoca a premissa de que a participação no projecto teve efectivamente lugar e que a estação sismológica da rede WWSSN funcionou durante algum tempo. Kai-Henrik Barth diz-nos que "During the early 1960s, US Coast and Geodetic Survey employees installed the network's 120 standardized seismic stations in over 60 countries"4, mas não esclarece no que concerne ao processo de instalação em si nem quanto ao funcionamento do mesmo em cada uma das instituições intervenientes após a instalação, algo que se tentou deslindar, como, de resto, aconteceu também com as identidades dos técnicos envolvidos, e o funcionamento da própria estação.

Olhando por outro prisma, diferentes actuações paralelas foram analisadas para que se obtivesse um escopo completo da presença portuguesa na rede WWSSN. Não ignorando a tutela da Faculdade de Ciências da Universidade do Porto, um programa como a estação sismológica teria certamente sido reportado às unidades orgânicas superiores na hierarquia da Universidade, o que levou a uma demanda quanto ao envolvimento da reitoria da Universidade do Porto e da Faculdade de Ciências no projecto, ou até de outras instituições, como por exemplo, a nível estatal.

Claro está que o desenho deste intento não é totalmente inocente. Se, por um lado, “A inserção de Portugal em organizações internacionais, nomeadamente a partir dos anos 60 , veio trazer um forte estímulo ao desenvolvimento do sistema científico e tecnológico nacional e influenciar decisivamente a sua própria configuração" ${ }^{5}$, a mesma década foi também marcada por um arrefecimento das relações luso-americanas. José Mariano Gago et alia fazem notar que a questão colonial como conduzida pelo governo salazarista não era do agrado da Administração Kennedy, que entrava na Sala Oval como figura principal da cena política americana em 1961.

Salazar tinha especial receio daquilo a que chamava o "deslocamento do centro da política mundial para o Atlântico" entendendo por isto o grande aumento do poder relativo dos EUA, que avançou para Ocidente e Oriente. Os EUA eram, nas palavras de Salazar, "um povo iluminado, não por Deus, mas pela lâmpada eléctrica", que tinha uma especial incompreensão dos valores e tradições da Europa e parecia apostado em destruir os seus impérios tradicionais. ${ }^{6}$

Não sendo um fervoroso apoiante dos americanos e sabendo da reprovação com que o governo americano via a possessão de colónias, Salazar entrava numa década de difícil

\footnotetext{
${ }^{4}$ BARTH, Kai-Henrik - "The Politics of Seismology: Nuclear Testing, Arms Control, and the Transformation of a Discipline”. Social Studies of Science. [Em Linha] Canadá: Queen's University. Vol. 33, nº 5 (2003), p. 759.

${ }^{5}$ GAGO, José Mariano [et al.] - "A Ciência e a Defesa em Portugal - Elementos para uma agenda de estudos futuros", in BARATA, Manuel Themudo; TEIXEIRA, Nuno Severiano (dir.) - Nova História Militar de Portugal. Lisboa: Círculo de Leitores, 2004. Vol. 5, p. 491.

${ }^{6}$ TELO, António José - "Os Anos da NATO (1946-1959)", in BARATA, Manuel Themudo; TEIXEIRA, Nuno Severiano (dir.) - Nova História Militar de Portugal. Lisboa: Círculo de Leitores, 2004. Vol. 4, pp. 437-438.
} 
relacionamento com os Estados Unidos. "A partir de 1961 altera-se, significativamente, o empenhamento atlântico, suspendem-se os compromissos com a NATO e a questão colonial torna-se a preocupação quase exclusiva da política externa portuguesa"7 . Por conseguinte, no trapézio a meio caminho entre o avanço científico e tecnológico e a política de afastamento dos americanos, tornou-se essencial para esta investigação iluminar o lado do espectro em se encontrava a rede WWSSN na opinião das altas instâncias do poder, se da rede tiveram conhecimento ou se quanto a ela emitiram alguma vez qualquer parecer.

Por fim, mantendo em vista o contexto de Guerra Fria e respectivas implicações no estudo da sismologia, a principal força motriz deste exercício foi o tentame de alcançar uma explicação satisfatória quanto ao objectivo da rede WWSSN em Portugal - ciência, política, estratégia - terá sido a combinação efectivamente de linhas ténues?

A análise intensiva das fontes descritas constituiu o método de pesquisa central desta investigação. Os dados extraídos do corpo epistolar, uma vez sintetizados, foram alvo de um processo de nova criação textual que teve na sua génese o estudo das fontes primárias e o cruzamento da informação obtida com a bibliografia consultada.

Vale a pena relembrar que a pesquisa bibliográfica levada a cabo permite considerar que a rede WWSSN não foi ainda devidamente perquirida, pelo que não é extenso o conjunto de estudos que se centra no assunto. Contudo, é de realçar o valor do já mencionado texto WorldWide Standardized Seismograph Network: A Data Users Guide ${ }^{8}$, de Jon Peterson e Charles R. Hutt, um documento elaborado em 2014, que traça a história da rede WWSSN e a sua configuração, prefigurando-se como uma cristalização documental do impacto que a rede teve nos avanços que a sismologia sofreu na segunda metade do século XX.

As anyone who has fielded a seismic experiment knows, it is very difficult to collect good data and a tragedy when the data are lost either though instrument malfunction or collection errors. The WWSSN was a grand experiment that generated an unprecedented collection of high quality, continuous data from approximately 100 stations around the world. This alone makes it one of seismology's best success stories. ${ }^{9}$

Um outro artigo, de Kai-Henrik Barth, igualmente mencionado, com o nome de "The Politics of Seismology: Nuclear Testing, Arms Control, and the Transformation of a Discipline" ${ }^{10}$, não se foca tanto na vertente técnica, nem só na rede WWSSN, antes apresenta o panorama da sismologia no início da Guerra Fria e a evolução que foi sofrendo ao longo da

\footnotetext{
${ }^{7}$ TEIXEIRA, Nuno Severiano - "Portugal e a Guerra Fria", in BARATA, Manuel Themudo; TEIXEIRA, Nuno Severiano (dir.) - Nova História Militar de Portugal. Lisboa: Círculo de Leitores, 2004. Vol. 4, p. 64.

${ }^{8}$ PETERSON; HUTT - op. cit.

${ }^{9}$ Idem, p. iii.

${ }^{10}$ BARTH - op. cit.
} 
última. Mais ainda, introduz o assunto da intervenção científica no armamento nuclear, que seria mais tarde secundada pela acção política, o que, por sua vez, levaria à criação da rede WWSSN. É, portanto, uma elaborada e aprofundada história da génese da rede em que o IGUP viria a participar, que permite perceber o motivo da sua existência e aplicação, indo desde as premissas que moldaram a Guerra Fria, como o medo nuclear, até ao desenvolvimento posterior da ciência sismológica, passando por acordos internacionais científicos e políticos, como a Convenção de Genebra de 1958 e pelo Vela Uniform Project.

Quanto ao IGUP em específico, são de realçar os títulos "Meteorological (and other) Instruments Revealed: The Collection of the Geophysical Institute of Porto University" "11 de Marisa L. Monteiro e Miguel F. O Soares, e "Instituto Geofísico da Universidade do Porto: Passado e Futuro"12 de Helena Sant'Ovaia, actual directora do IGUP, e Rui Moura. Estes artigos relevam pelo seu contributo enquanto testemunhos actuais da história do IGUP, mencionando brevemente a rede WWSSN.

Para a construção da história do Instituto duas obras de publicação francamente mais recuada no tempo não perdem a sua pertinência para esta investigação: Observatório da Serra do Pilar: breves notas históricas, estado actual, desenvolvimento ${ }^{13}$ (1929) de Álvaro R. Machado, e Instituto Geofísico: Esboço Histórico ${ }^{14}$ (1969) de Carlos Coutinho Braga. Ambos os autores foram directores do IGUP, Machado entre 1920 e 1922 e Coutinho Braga entre 1959 e 1969. Uma e outra obras são descrições detalhadas da actuação do IGUP e do seu papel na cena científica nacional, fruindo de uma elaboração particularmente útil por terem sido escritas por homens que devotaram parte da sua vida ao Instituto. O livro de Carlos Coutinho Braga, tal como os artigos de Monteiro e Soares e de Sant'Ovaia e Moura, faz também uma breve menção à rede WWSSN, mas não suficiente para um conhecimento demasiado detalhado do funcionamento da mesma.

Além do relatório de estágio de Augusto Silva Lima Gomes dos Santos, Mestre em História e Património pela Faculdade de Letras da Universidade do Porto ${ }^{15}$, não existe, tanto

\footnotetext{
${ }^{11}$ MONTEIRO, Marisa L.; SOARES, Miguel F. O. - "Meteorological (and other) Instruments Revealed: The Collection of the Geophysical Institute of Porto University". Bulletin of the Scientific Instrument Society. Londres: Scientific Instrument Society. ISSN 0956-8271. No 104 (2010), pp. 17-21.

12 SANT'OVAIA, Helena; MOURA, Rui - "Instituto Geofísico da Universidade do Porto: Passado e Futuro". Geocore: Revista do Núcleo de Geologia do Porto. Porto: Faculdade de Ciências da Universidade do Porto. № 2 (2017), pp. 10-12.

13 MACHADO, Álvaro R. - Observatório da Serra do Pilar: breves notas históricas, estado actual, desenvolvimento. Porto: Publicações do Observatório da Serra do Pilar, 1929.

14 BRAGA - op. cit.

${ }^{15}$ SANTOS, Augusto Silva Lima Gomes dos - O arquivo do Instituto Geofísico (Observatório Meteorológico da Serra do Pilar) da Universidade do Porto-um estudo sistémico. [Em Linha] Porto: Universidade do Porto, 2020. Relatório de Estágio.
} 
quanto foi possível apurar, um artigo que se debruce somente na rede da perspectiva do IGUP. Caberá, espera-se, a esta investigação colmatar essa lacuna bibliográfica e fomentar a continuação do estudo do Instituto Geofísico da Universidade do Porto.

\section{Contextualização Histórica}

Com o término da Segunda Guerra Mundial, os Estados Unidos da América e a URSS eram as únicas duas nações com algum poder remanescente, ainda que, se de uma corrida se tratava, e tratar-se-ia, efectivamente, os EUA haviam saído do período bélico em melhores condições que a União Soviética, a nível de poderio científico e armamento, com armas nucleares mas, sobretudo, a nível demográfico. Não obstante, tal não poupava os americanos de preocupações, dado que a sua prosperidade dependia de uma Europa que se encontrava devastada e avessa a um mercado livre.

Nessa mesma altura, a União Soviética encorajava o estabelecimento de governos comunistas pró-soviéticos, especialmente se os países em que tal se conseguisse fossem os mesmos que impedissem o avanço alemão para Leste. Esse ideal estava longe de qualquer ambição americana para o futuro próximo, uma vez que o avanço e a proliferação de regimes comunistas significariam uma demasiado provável perda de mercados e do continente de escoamento de produtos que era a Europa. O objectivo rapidamente se tornou bloquear a expansão dos poderes soviéticos e menorizar, tanto quanto possível, a influência do Kremlin sobre o mundo. Havia uma circunscrição americana para aquilo que poderia ser o espaço de actuação do comunismo, que em pouco ou quase nada coincidia com a vontade expansionista soviética. Assim, a vitória americana sobre os ventos de Leste passaria por afirmar o modelo capitalista e livre sobre o qual fora construída a América, mais do que somente mostrar a falta de liberdade que do comunismo advinha. A garantia da liberdade segundo a definição americana poderia passar por intervenção governamental na economia e na sua regulação, mas não num controlo absoluto, como se via na União Soviética. No mundo ocidental de que os Estados Unidos se haviam tornado pináculo no final da guerra, eram assegurados aos cidadãos direitos como a propriedade, a justiça aplicada com imparcialidade, liberdade de expressão e de imprensa, ou seja, "o princípio subjacente do governo seria a esperança, não o medo. Nenhuma destas condições existia na União Soviética, nos seus satélites ou nos territórios que ocupava e administrava" ${ }^{\prime \prime}$.

Com esta premissa em mente, o presidente Harry S. Truman e a sua administração elaboraram um plano de contenção do avanço das ideias soviéticas, conhecido como "Doutrina

\footnotetext{
${ }^{16}$ GADDIS, John Lewis - A Guerra Fria. Lisboa: Edições 70, 2007, p. 111.
} 
Truman", em que se almejava reconstruir a Europa segundo os preceitos americanos do desenvolvimento, e ainda com o objectivo de esta não resvalasse para o lado de influência russa. Temiase que a fome e a pobreza "pudessem levar os europeus a eleger para o governo os seus próprios comunistas, que cumpririam então obedientemente os desígnios de Moscovo"17. A doutrina materializava-se e aprofundava-se com o Plano Marshall, resposta prática dada à turbulência económica que a Europa vivia e que facilmente seria terreno fértil para o avanço do comunismo.

A ideia era dar um empurrão às economias europeias - e, simultaneamente, à do Japão - através de uma forte injecção de capitais americanos, mas também envolver os beneficiários, desde o início, nas decisões sobre a forma de como a ajuda seria utilizada. A única condição era que trabalhassem juntos, "que os velhos antagonismos se esbatessem face aos novos perigos"18.

Perigos esses que se afiguravam demasiado sérios. No final da década de quarenta do século XX, a Alemanha estava já dividida em duas nações e uma bomba atómica havia sido detonada pelos soviéticos. Encetava-se uma guerra de duas grandes facções adversas, o Oeste e o seu modelo de capitalismo livre, e o Leste, construído sobre os pilares do comunismo. Aquilo que os americanos chamavam de red scare justificaria as intervenções que se seguiriam e o investimento feito pelo governo americano em educação, tecnologia e investigação científica. O medo atómico sustentava o novo conceito de liberdade assente na fidelidade a um Estado que conseguisse prevenir a destruição massiva ${ }^{19}$, medo que seria bem sintetizado pelo escritor norteamericano William Faulkner no seu discurso de aceitação do Prémio Nobel, em 1950.

Our tragedy today is a general and universal physical fear so long sustained by now that we can even bear it. There are no longer problems of the spirit. There is only the question: When will I be blown up? ${ }^{20}$

O pavor de um futuro destruído pela ameaça nuclear levou a que ambas as nações rivais investissem seriamente em investigação científica e tecnológica, de modo a garantir que a superioridade no desenvolvimento de uma arma tão letal fosse suficiente para desencorajar o inimigo a detonar uma bomba sua. Barth, em "The Politics of Seismology: Nuclear Testing, Arms Control, and the Transformation of a Discipline"21, explica como a ciência, em particular a sismologia, foi essencial para que a guerra se mantivesse fria. No final da década de 1950, negociações para o controlo de armas nucleares entre os Estados Unidos da América e a União Soviética eram compostas por discussões para a monitorização de testes nucleares em que

\footnotetext{
${ }^{17}$ Idem, p. 42.

${ }^{18}$ Idem, p. 111.

${ }^{19}$ Cf. HOBSBAWM, Eric - Age of Extremes: The Short Twentieth Century, 1914-1991. Londres: Abacus, 1995 , pp. 225-256.

${ }^{20}$ FAULKNER, William - Discurso proferido no Banquete do Nobel. Estocolmo, 10 de Dezembro de 1950.

${ }^{21}$ BARTH - op. cit.
} 
cientistas de ambas as nações concordavam que as explosões subterrâneas eram as mais difíceis de supervisionar e que a única forma de garantir maior intelecção era desenvolver novas técnicas sismológicas, uma vez que as existentes à altura das negociações não eram suficientes para detectar com segurança pequenos testes que fossem levados a cabo no subsolo. Na senda da percepção deste "atraso" tecnológico e científico, "President Eisenhower initiated a comprehensive research and development program in seismology in 1959, which became known as Project Vela Uniform"22.

Eisenhower foi sugerindo não poucas vezes a Nikita Khrushchev que cientistas de ambos os pólos da questão se reunissem com o intuito de resolver alguns dos problemas técnicos relativos à detecção de testes nucleares antes de qualquer arranjo político-diplomático. Ainda que para Khrushchev não fizesse tanto sentido assim que problemas políticos fossem resolvidos em campos de batalha científicos, isso não foi suficiente para o impedir de anuir a tal reunião em Abril de $1958^{23}$.

No dia 1 de Julho desse ano, especialistas na área da sismologia reuniram-se em Genebra, na Suíça. O acordo entre ambas as delegações chegaria no dia 21 de Agosto, com a conclusão de que o controlo de testes e experiências nucleares era tecnicamente possível dentro de algumas limitações.

The experts proposed a control system of 170 detection stations worldwide, augmented by ten stations located on ships to cover large areas of the world's oceans. They specified various means for the detection of nuclear explosions in the atmosphere, the oceans, on the earth's surface, and underground. As it turned out, detecting underground explosions became the most contentious issue. ${ }^{24}$

Após a Conferência de Genebra, e após submissão prévia do Berkner Report ${ }^{25}$, que seria a base do sobredito projecto organizado pelo Departamento de Defesa norte-americano, muitos sismólogos receberam grandes bolsas e apoios estatais com contractos para fomentar a investigação na área. "Equipped with hundreds of thousands, and sometimes millions, of research dollars, seismology programs around the country accelerated research activities"26. Um dos sistemas de instrumentação sismológica criados no âmbito do projecto Vela foi uma

\footnotetext{
${ }^{22}$ Idem, p. 744.

${ }^{23}$ Idem, pp. 749-750.

${ }^{24}$ Idem, p. 750.

25 "A quickly organized panel of seismological experts, chaired by the experienced science administrator Lloyd V. Berkner, developed a grand research plan for seismology. [...] The Berkner Report's summary was written by leading seismologists Frank Press, Jack Oliver, and Carl Romney. The three seismologists laid out a master plan for future research in seismology and suggested that 'major advances in [seismology] could be realized only if the level of research were significantly increased'». (apud BARTH - op. cit., pp. 751-752).

${ }^{26}$ BARTH - op. cit., p. 744.
} 
rede global de investigação, que ficaria conhecida como World-Wide Standard Seismograph Network (WWSSN).

The development, installation, and operation of the WWSSN, the largest seismic instrument built to that date, exemplifies the scale of Vela's seismic systems. During the early 1960s, US Coast and Geodetic Survey employees installed the network's 120 standardized seismic stations in over 60 countries. ${ }^{27}$

Mais do que o seu papel a detectar testes nucleares, que Barth diz ser de discutível eficácia devido ao equipamento usado e aos locais escolhidos para montar as estações, o valor e o legado do programa são inquestionavelmente importantes. "The WWSSN recorded thousands of earthquakes each year, providing a wealth of high-quality data for a whole generation of scientists" 28 , além de ter sido, para muitos dos países que participaram na rede, a primeira oportunidade de dar início a um programa de investigação sismológica. Um desses países seria Portugal, com estação instalada no alto da Serra Pilar, onde se localiza o Instituto Geofísico da Universidade do Porto.

\section{O convite, a selecção e a motivação por detrás do programa}

A 12 de Julho de 1960 chegava às instalações do Instituto Geofísico da Universidade do Porto uma carta de duas páginas endereçada aos directores da instituição, emitida no dia 5 desse mesmo mês, pelo U. S. Department of Commerce - Coast and Geodetic Survey, a partir de Washington D. C., que começava da seguinte forma:

The United States is undertaking an extensive program to encourage the conduct and expansion of fundamental research in seismology. It will, in so far as possible, include investigations in all fields of this science. To initiate the effort the U. S. Coast and Geodetic Survey is to instrument approximately 125 stations in all areas of the world. The objective is to provide standardized instrumentation capable of furnishing quantitative data for the studies of world seismicity, earthquake mechanism, seismic wave propagation and energy determinations. ${ }^{29}$

O início da carta explicava a essência do que seria a World-Wide Standard Seismograph Network, declarando desde logo um objectivo claramente científico e de desenvolvimento técnico a partir do fornecimento de instrumentação padronizada capaz de fornecer dados quantitativos para os estudos de sismicidade mundial, mecanismos de terramotos, propagação de ondas sísmicas e determinações de energia. Explicava-se de seguida que os instrumentos consistiriam em três sismógrafos electromagnéticos de três componentes de curto período e outras três de componentes de longo período. Os sismógrafos seriam calibrados e as suas

\footnotetext{
${ }^{27}$ Idem, p. 759.

${ }^{28}$ Idem, p. 760.

${ }^{29}$ AIGUP - Carta do director do U. S. Coast and Geodetic Survey à direcção do IGUP, Washington D. C., 12.06.1960.
} 
características seriam idênticas em cada uma das estações. Pretendia-se que o equipamento fosse atribuído não só às estações seleccionadas que em todas as regiões do mundo tivessem sido até então participantes activas e de confiança em trabalho sismológico, mas também a instituições que mostrassem forte potencial para investigação na área da sismologia e que pudessem dar "adequate assurances of seismic growth" 30 .

É de seguida sublinhado que as estações recipientes teriam de fornecer um local que albergasse a estação, cofres para a instalação e material e energia necessários para a operação, além de futuramente assegurar pessoal operacional e fundos necessários para a manutenção do equipamento da estação. Deste modo, o U. S. Coast and Geodetic Survey (C\&GS) propunhase a oferecer equipamento e a sua instalação, salvaguardando que os gastos de manutenção e de operação que se seguissem ficariam ao cargo da estação recipiente.

All station directors will be requested to make their seismograms available to competent scientist and to send the originals or reproducible copies of each seismogram to the Coast and Geodetic Survey, where the seismograms would be available to all seismologists. ${ }^{31}$

Adiante, requeria-se às estações participantes que colocassem ao serviço do programa "cientistas competentes" e que os sismogramas obtidos através dos instrumentos pelo departamento americano oferecidos fossem remetidos ao U. S. Coast and Geodetic Survey para serem posteriormente disponibilizados a todos os sismologistas. Desde o primeiro momento de contacto com o IGUP, a missão é declaradamente científica e até cooperativa, uma vez que todos os sismólogos usufruiriam do programa. Claro está que "all seismologists" é uma definição de grupo algo lata que pouco deixa antever de facto que cientistas tomariam partido da informação reunida, se somente americanos, todos os envolvidos no projecto a nível mundial, ou se a informação seria efectivamente de acesso público sem restrições de consulta, parecendo esta última hipótese de menores viabilidade e coerência.

A carta continha como anexo $0^{32}$ um relatório da National Academy of Sciences acerca das diferentes fases do programa e um inquérito cujo objectivo era determinar "the interest and capabilities of seismograph stations for participation in this instrumentation program" 33 , algo a decidir por um painel de sismólogos que seleccionariam as estações participantes. Ou seja, não se tratava ainda de um convite para participação no programa, mas para participação no concurso de selecção, pelo que se pode inferir que existiria um perfil algo específico que as

\footnotetext{
${ }^{30}$ Idem.

${ }^{31}$ Idem.

${ }^{32}$ Nenhum dos dois anexos se encontra no arquivo ao IGUP, ou foi identificado como tal.

${ }^{33}$ AIGUP - Carta do director do U. S. Coast and Geodetic Survey à direcção do IGUP, Washington D. C., 12.06.1960.
} 
estações futuramente participantes na rede teriam de ter. A carta era assinada por " $\mathrm{H}$. Arnold Karo, Rear Admiral, C\&GS Director".

$\mathrm{Na}$ resposta ao inquérito enviada pelo director do IGUP ${ }^{34}$, não datada, referiam-se valores de aspectos técnicos da área da sismologia, a distância ao Oceano Atlântico de cerca de 5600m desde o edifício, situado nas coordenadas $08^{\circ} 36^{\prime}$ 08' ' W G., $41^{\circ} 08^{\prime}$ ' 19' ' N, e a acção do vento no local.

A equipa técnica era composta por quatro sismólogos ${ }^{35}$ : Dr. Artur de Vasconcelos Craveiro, licenciado em Ciências Matemáticas, primeiro meteorologista, com experiência suficiente, fazendo parte da equipa do Instituto há 25 anos; António Alves de Castro, segundo observador, com alguma experiência, fazendo parte da equipa do Instituto há 12 anos; João Lopes Pires, primeiro meteorologista assistente, com alguma experiência, fazendo parte da equipa do Instituto há 11 anos; e Manuel Alfredo Lopes de Passos Ribeiro, segundo meteorologista, com alguma experiência, fazendo parte da equipa do Instituto há 10 anos.

Dos sismógrafos tomavam conta Jorge Ramos de Pinas e Henrique Rodrigues Mendes, ambos segundos meteorologistas assistentes. O cargo de fabricante de instrumentos e de maquinista era ocupado por José da Cunha Teixeira.

O Professor Doutor Carlos de Azevedo Coutinho Braga, director do Instituto e professor catedrático da Universidade do Porto, escrevia ainda que o IGUP tinha espaço suficiente para albergar a instalação dos instrumentos e que seria apenas necessário fazer alguns arranjos que seguiam descriminados nos planos anexados. A aceitação dependeria do dinheiro que o Departamento Financeiro pudesse disponibilizar. A resposta definitiva ficava, pois, dependente da possibilidade de adquirir equipamento adicional e de autorização à mudança orçamental.

Demoraria alguns meses até que novidades viessem do U. S. Department of Commerce and Geodetic Survey, oito mais precisamente. A 21 de Fevereiro de 1961 havia já um maior pendor político na explicitação da criação da rede resultante do trabalho de um comité de sismólogos americanos "established in April 1960 by the National Academy of Sciences - a National Research Council to advise the United States Government in the establishment of an improved world-wide network of seismographs" ${ }^{36}$. Tal surge, de certa maneira, no seguimento de algo que já vinha ganhando terreno desde os anos cinquenta: a tentativa de os cientistas terem alguma influência ou possibilidade de aconselhamento no tocante à acção política.

Consequently, in 1955, a number of the world's leading seismologists proposed to the Governments of the USA, the UK, and the Soviet Union to set off four nuclear explosions

\footnotetext{
${ }^{34}$ AIGUP - Resposta ao inquérito enviado pelo U.S. Coast and Geodetic Survey, Vila Nova de Gaia, c. 1960.

${ }^{35}$ Idem.

${ }^{36}$ Idem.
} 
purely for seismological research [...] While this proposal failed, it was the first major effort by seismologists to advocate the use of nuclear explosions for scientific purposes. Subsequently, in the 1960s, a number of nuclear explosions were set off as part of the Vela Uniform program specifically to test seismological theories. ${ }^{37}$

Segundo esta carta, as 125 estações eram escolhidas com base na distribuição geográfica e na demonstração de interesse na investigação sismológica; assim se entende a escolha de Portugal, que provavelmente asseguraria a sua zona do globo e se deduz que o IGUP era tido como uma estação de grande qualidade e ambição científica.

Os objectivos do programa voltam a surgir novamente num enquadramento totalmente tecnológico e de desenvolvimento técnico. Pode-se ler que o propósito do programa era encorajar e manter um alto nível de interesse e cooperação internacionais no campo da sismologia, tendo em consideração a possibilidade de:

a) Develop a better understanding of the world's seismicity, both to degree and nature of the source. A greater knowledge in this area may ultimately lead to improved prediction of destructive earthquakes.

b) Develop a greatly improved knowledge of the world's crust and mantle, particularly with regard to the number, thickness, and nature of the major layers therein.

c) Improve world knowledge of wave propagation characteristics through the earth, including the determination of accurate values for regional travel times.

d) Provide much improved data for a comparison of all types of seismic waves. ${ }^{38}$

Mesmo que "destructive earthquakes" se pudesse tratar de um eufemismo nuclear, o resto da carta de duas páginas é um compromisso científico de fazer crescer e vingar a sismologia. Não são declarados objectivos políticos e muito menos se menciona a Guerra Fria ou testes nucleares, que pareceram, à medida que se avançou nesta análise, mais a causa da criação da rede que um objectivo a ter em conta.

A carta terminava com a notícia de que o Instituto havia sido escolhido para participar no projecto e que o programa de instalação teria início no dia 1 de Julho de 1961, devendo estar já terminado e em funcionamento a partir do mês de Setembro de 1962. Os instrumentos seriam instalados por uma equipa enviada pelo U. S. Coast and Geodetic Survey, que, se necessário, formaria o pessoal do IGUP quanto à laboração dos instrumentos. Ficaria ao encargo do lado americano aspectos como autorizações de trabalho e a expedição de tudo quanto fosse essencial para a instalação.

A resposta do director do IGUP, cuja data de envio não aparece na respectiva carta, era de agradecimento cauteloso, devido a estar dependente "on our being duly authorized by the

\footnotetext{
${ }^{37}$ BARTH - op. cit., p. 748.

${ }^{38}$ AIGUP - Carta do director do U. S: Coast and Geodetic Survey a Carlos Coutinho Braga, Washington D. C., 21.02.1961.
} 
respective State Department and granted the necessary funds"39. Carlos Coutinho Braga não augurava uma resposta breve, uma vez que o IGUP continuava a necessitar de obter dinheiro para a construção do bunker em que o equipamento seria instalado e alguns milhares de escudos por mês para manutenção da estação, que seriam gastos em papel de registo e energia eléctrica, por exemplo. Indirectamente, deste modo se afirmava a necessidade de informar as instituições das quais dependia o Instituto quanto à presença da rede americana em Portugal.

Nesta sintonia, a 27 de Março de 1961, Carlos Coutinho Braga, em duas páginas enviadas ao "Exmo. Senhor Reitor da Universidade do Porto", dava a notícia da selecção do Instituto como estação recipiente da rede WWSSN. Explicava sumariamente o projecto, como este surgira e quais os seus objectivos, pedindo "a V. Ex. a para, junto das entidades competentes se dignar providenciar que seja concedida a indispensável autorização para se aceitar o material em causa" ${ }^{40}$. Mais que isso, era requerido ao reitor que transmitisse superiormente que para o efeito seria necessária uma autorização do Ministério das Obras Públicas para construção de uma dependência no terreno do Instituto para instalação do equipamento, uma verba inscrita no Orçamento Geral do Estado para aquisição de artigos necessários à investigação de, pelo menos, 4000 escudos mensais, e uma maior verba do que aquela de que o Instituto usufruía então para despesas com água, luz, aquecimento e limpeza de pelo menos 800 escudos mensais, "a bem da Nação". A 5 de Julho o reitor reenviava um ofício da Direcção Geral do Ensino Superior e das Belas-Artes que comunicava que "por despachos de Sua Exa . o Ministro da Educação Nacional e de Sua Ex. ${ }^{\text {a }}$ o Ministro das Finanças [...] foram aceites para o Estado os seis componentes de sismómetro, respectivos registadores e todo o material acessório que a Academia das Ciências dos Estados Unidos da América do Norte pretende oferecer ao Instituo

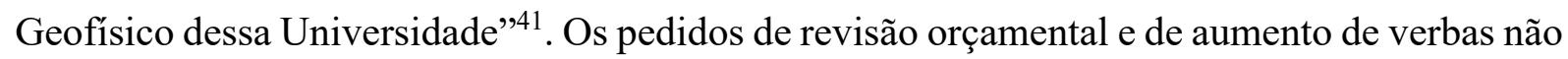
ficariam por aqui. Os custos mostrar-se-iam crescentes à medida que o tempo passava, pois mais pedidos foram feitos em 1962, a 12 de Janeiro, a 5 de Abril, a 11 de Maio e a 12 de Outubro, relacionados com gastos em papel registador, energia, transporte de material e carências associadas à construção da dependência para os sismógrafos, entre outros aspectos administrativos.

É de realçar o valoroso papel que o reitor da Universidade do Porto representou como intermediário entre o IGUP e as devidas entidades, tornando mais célere e profícuo o processo de decisão. A mesma relevância se pode conferir à reitoria, em virtude de, a partir do momento em que toma conhecimento do projecto, servir de agente no seu desenvolvimento.

\footnotetext{
${ }^{39}$ AIGUP - Carta de Carlos Coutinho Braga ao director do U. S. Coast and Geodetic Survey, Vila Nova de Gaia, c. Fevereiro de 1961.

${ }^{40}$ AIGUP - Carta de Carlos Coutinho Braga ao Reitor da Universidade do Porto, Vila Nova de Gaia, 27.03.1961.

${ }^{41}$ AIGUP - Carta do Reitor da Universidade do Porto a Carlos Coutinho Braga, Porto, 05.07.1961.
} 
Outrossim, mais do que meramente informar organismos do Estado português, a rede implicaria solicitações formais ao Ministério das Obras Públicas e, idealmente, alterações no Orçamento de Estado, numa decisão a ser tomada pelos Ministros das Finanças e da Educação Nacional. Decorre daqui que o Governo teve conhecimento da instalação da rede americana em Portugal e que não terão sido colocados entraves substanciais à instalação. Com efeito, a partir de 1961, a situação política entre Portugal e os Estados Unidos da América esfriava, mas as disputas que o Estado português pudesse ter com os EUA, devido à questão colonial e pelos conflitos da descolonização, não manchavam o avanço da ciência nacional.

\section{A disputa com Lisboa}

Tratados os problemas iniciais, outro surgia em Julho de 1961. Robert A. Earle, chefe do C\&GS de divisão de Geofísica, envia uma carta dirigida ao Professor H. Amorim Ferreira, director do Serviço Meteorológico Nacional, da qual enviou uma cópia também para Carlos Coutinho Braga. O C\&GS pedia ao Serviço Meteorológico Nacional para escolher uma estação em Portugal que recebesse um conjunto de sismógrafos ${ }^{42}$, porquanto o director teria respondido ao mesmo questionário a que o director do IGUP respondera, declarando, no entanto, que preferia que a estação receptora fosse a de Lisboa.

Após a aprovação do governo português para que o projecto fosse empreendido no Porto, uma nova decisão tinha de ser tomada acerca de qual das duas instituições deveria acolher o programa, dado que apenas uma estação podia ser instalada no país. Consequentemente, Robert A. Earle pedia que os dois directores chegassem a um acordo amigável sobre qual das estações seria a representante de Portugal no programa internacional.

A vontade que Carlos Coutinho Braga demonstra na sua exposição dos assuntos ao director do Serviço Meteorológico Nacional de 2 Agosto de 1961 deixa entrever o desejo de que o IGUP fosse o recipiente português da estação americana. Após descrever tudo o que acontecera até então, o convite, os pedidos e a resposta já recebida que cria ser final, a sua missiva termina do seguinte modo:

Nestas condições agradecia a V. $\mathrm{Ex}^{\mathrm{a}}$ se digne informar-me do que entender por conveniente na certeza de que muito gostaria de chegar a uma solução amigável embora tanto eu, como Director do Instituto Geofísico, bem assim o Conselho Escolar da Faculdade de Ciências do Porto insistem em não modificar o que já está decidido pelas instâncias superiores. ${ }^{43}$

A contenda que principiava foi intervalada por uma visita de um enviado do U. S. Coast and Geodetic Survey, Dr. William Green. O director do IGUP, numa carta de 10 de Novembro,

\footnotetext{
${ }^{42}$ AIGUP - Carta do director do U. S. Coast and Geodetic Survey ao director do Serviço Meteorológico Nacional, H. Amorim Ferreira, Washington D. C., 25.07.1961.

${ }^{43} \mathrm{Idem}$.
} 
agradecia a visita ao Instituto e informava o departamento americano de que se concluíra na visita de Dr. Green que apenas três meses seriam necessários para a construção do bunker em que se instalariam os sismógrafos e que o início da construção dependia só da confirmação de que os instrumentos seriam efectivamente lá instalados ${ }^{44}$. E o director português não via por que motivo a confirmação não haveria de ser dada.

As to this matter I don't think that any doubt may arise, as Dr. Green has recognized himself, that Oporto is the quietest place in relation to the quantity of noise (granitic region). In connection with the necessary people to work with the instruments I don't think any problem will occur. ${ }^{45}$

A partir destas asserções, é conspícuo que os esforços de conversação e a defesa activa da sua instituição mostram que Carlos Braga Coutinho ficara realmente agradado com a oferta e que muito desejava que a estação fosse instalada na Serra do Pilar. Não há nas cartas qualquer palavra que contradiga uma vontade evidente de levar a cabo o projecto, o que não é de estranhar a maior potência mundial à época oferecia equipamento de ponta e a possibilidade de participar num projecto à escala internacional que prometia ser uma mudança no papel da sismologia mundialmente. Ademais, o IGUP não perderia exactamente autonomia, dado que parte significativa do orçamento permaneceria sob controlo português e os técnicos seriam "os da casa".

A cereja no topo de bolo chegava por correio a 30 de Novembro de 1962. Robert A. Earle enviava uma carta e a sua cópia aos respectivos directores das instituições em competição. O conteúdo esclarece que os directores portugueses não haviam chegado a um acordo e que um pedido tinha sido feito ao U. S. Coast and Geodetic Survey para que fosse o departamento a decidir. A escolha, declarava, havia recaído sobre o IGUP, pelas seguintes razões:

a) The observatory at Serra do Pilar is more isolated from the artificial disturbances of the city than is the site at Lisbon.

b) The geological foundation promises to be more stable seismically.

c) They plan to construct a new vault suitable for housing the standard system. As you have assured us, Dr. Braga's staff, though small, is very competent and interested in seismology. ${ }^{46}$

Porto era eleito em detrimento de Lisboa pelo seu maior isolamento da agitação citadina, pelo material geológico mais estável sismologicamente e pela prontidão para construir uma espécie de cofre ou forte que servisse de lugar de funcionamento da estação, entregue a cientistas competentes e muito interessados em sismologia. A 6 de Dezembro, Carlos Coutinho

\footnotetext{
${ }^{44}$ AIGUP - Carta de Carlos Coutinho Braga ao director do U. S. Coast and Geodetic Survey, Vila Nova de Gaia, 10.11.1961.

${ }^{45} \mathrm{Idem}$.

${ }^{46}$ AIGUP - Cópia da carta do director do U. S. Coast and Geodetic Survey ao director do Serviço Nacional de Meteorologia, Washington D. C, 30.11.1961.
} 
Braga informava o reitor da Universidade do Porto ser definitiva e estar assegurada a instalação dos aparelhos no Instituto, fazendo também saber que pedira à Direcção dos Edifícios do Norte que se iniciasse o "quanto antes a construção das dependências"47 para instalação da aparelhagem.

\section{Do papel à realidade}

Uma vez pronta a construção da dita dependência, faltava um passo para ultimar a recepção do material dado pelo departamento americano: conseguir a "isenção de direitos e de mais imposições para os seis componentes de sismómetro [...], respectivos registadores e todo o material acessório" ${ }^{48}$, pedido que é feito ao reitor a 9 de Março de 1962, para que o transmitisse ao Ministro das Finanças. A isenção era concedida a 1 de Maio. Mais uma vez, o poder estatal permitia a "penetração" de uma rede americana em Portugal. De todos os quadrantes envolvidos, a reacção é, pelo menos segundo os documentos oficiais, sempre positiva e a acção tão célere quanto possível. De igual modo, a 21 do mesmo mês ${ }^{49}$, o Ministério das Obras Públicas, através da Direcção dos Serviços de Construção e da Direcção dos Edifícios do Norte, abria um concurso público para arrematação da empreitada da construção para albergar os sismógrafos americanos, que seria, em Julho, adjudicada a Serafim da Silva Carvalho $^{50}$. Os planos da construção foram depois enviados ao U. S. Coast and Geodetic Survey e bastante bem recebidos da parte americana. Numa carta de 27 de Julho, Robert A. Earle escrevia "The plans are excellent and we look forward to installing your new instruments"

O equipamento abandonava solo americano na primeira semana de Novembro e chegava a Vila Nova de Gaia a 12 de Dezembro. Três meses depois, o projecto avançava com grande sucesso.

É com imenso prazer que comunico a V. Ex ${ }^{\mathrm{a}}$ que a equipa de técnicos americanos que se encontra aqui procedendo à instalação da estação sismológica oferecida a este Instituto pelo Governo dos Estados-Unidos e que é constituída pelos geofísicos srs. William Chapman e Bryant Hill, se têm referido à construção do edifício feita através da Direcção em que V. $\mathrm{Ex}^{\mathrm{a}}$ proficientemente orienta, nos termos mais elogiosos. Manifestaram mesmo os referidos geofísicos o seu muito interesse na obtenção de uma cópia do projecto respectivo que poderia, segundo eles nos disseram, vir a servir de modelo para futuras estações. ${ }^{52}$

Não se sabe ao certo quando ficou a estação pronta; sabe-se, sim, que a 26 Março, o Governador Civil do Porto, João de Brito Cunha, era obrigado a declinar o convite para visitar

\footnotetext{
${ }^{47}$ AIGUP - Carta de Carlos Coutinho Braga ao Reitor da Universidade do Porto, Vila Nova de Gaia, 06.12.1961.

${ }^{48}$ AIGUP - Carta de Carlos Coutinho Braga ao Reitor da Universidade do Porto, Vila Nova de Gaia, 09.03.1962.

${ }^{49}$ AIGUP - Edictal do concurso público para arrematação da empreitada da construção no IGUP, Lisboa, 21.03.1962.

${ }^{50}$ AIGUP - Carta do director dos Edifícios Nacionais do Norte a Carlos Coutinho Braga, Porto, 18.07.1962.

${ }^{51}$ AIGUP - Carta do director do U.S. Coast and Geodetic Survey a Carlos Coutinho Braga, Washington D. C., 27.07.1962.

${ }^{52}$ AIGUP - Carta de Carlos Coutinho Braga ao Director dos Edifícios Nacionais do Norte, Vila Nova de Gaia, 08.03.1963.
} 
a nova estação sismológica "em virtude de nesse dia estar em Lisboa em serviço oficial" 53 , e que, no dia 29 desse mês, o Presidente da Fundação Calouste Gulbenkian agradecia o mesmo convite, desta feita aceitando-o ${ }^{54}$.

O modo de envio dos sismogramas obtidos a partir dos instrumentos americanos é clarificado numa carta de 27 de Março de $1963^{55}$, em que o U. S. Coast and Geodetic Survey, na pessoa de Robert A. Earle, enviava mais etiquetas já com franquia assegurada para serem usadas no despacho aéreo dos registos sismográficos.

Carlos Coutinho Braga, cuja actuação enquanto director do IGUP compreendeu o período entre 1959 e 1969, escreveria, nesse último ano, uma espécie de memória sobre o IGUP enquanto instituição científica, fazendo no seu livro saber que a estação, "constituída por 3 componentes de sismómetro de "curto período" (componentes "Vertical", "N-S" e "E-W") e por outras tantas componentes de sismómetro de "longo período" (também "Vertical", "N-S" e "E-W")" "56, entrava em funcionamento no dia 1 de Abril de 1963. "Due to unique geological conditions, station $\mathrm{n}^{\mathrm{o}} 91$ (code name PTO) was installed in 1963 [...] and, apart from this one, there was only one station in the Iberian Peninsula, in Toledo"57.

\section{Conclusão}

Dois anos depois, em Dezembro de 1965, um diferente director do U. S. Coast and Geodetic Survey, James C. Tison, Jr., concedia título de propriedade do sismógrafo pelo departamento oferecido ao IGUP. A oferta inicial era então oficializada na sua plenitude, algo possível graças à participação de "well over 100 stations in operation" 58 . O beneplácito pela condução do projecto na estação portuguesa mantinha-se e era reiterado.

Let us also express our appreciation for the high-quality operation maintained by you and your colleagues. We feel that the contributions by observatories participating in the program will result in a continuous upgrading of data, and the science of seismology will benefit accordingly. ${ }^{59}$

A carta fazia-se acompanhar por um certificado de título concedido à estação PTO ${ }^{\circ}$ $91^{60}$ pelo Department of Commerce - Coast and Geodetic Survey. A tónica é mais uma vez colocada nos resultados obtidos a nível de dados sismológicos possibilitadores de um

\footnotetext{
${ }^{53}$ AIGUP - Carta do Governo Civil do Porto a Carlos Coutinho Braga, Porto, 26.03.1963.

${ }^{54}$ AIGUP - Carta do Presidente da Fundação Calouste Gulbenkian a Carlos Coutinho Braga, Lisboa, 29.03.1963.

${ }^{55}$ Carta do director do U. S. Coast and Geodetic Survey a Carlos Coutinho Braga, Washington D. C., 27.03.1963.

${ }^{56}$ BRAGA - op. cit., p. 337.

${ }^{57}$ MONTEIRO; SOARES - op. cit., p. 20.

${ }^{58}$ AIGUP - Carta do director do U. S. Coast and Geodetic Survey a Carlos Coutinho Braga, Washington D. C., 09.12.1965.

${ }^{59} \mathrm{Idem}$.

${ }^{60}$ AIGUP - Certificado de título outorgado pelo U. S. Coast and Geodetic Survey, Washington D. C., 09.12.1965.
} 
aprofundamento da investigação em sismologia - todo o planeamento e investimento resultava de uma enorme vontade por parte dos americanos, depois secundada pelas estações participantes, de fazer progredir esta área, cuja compreensão permitiu também o desenvolvimento da geologia, da física, da química, da matemática, e de diferentes ramos da tecnologia. Efectivamente, a Guerra Fria podia ter despoletado esta corrida científica, mas era também a causa de um crescimento que se tornaria autónomo, podendo-se dizer que "contribuiu decisivamente para a emergência de uma política científica, mas também para a divulgação das boas práticas de ciência e tecnologia entre nós" ${ }^{" 1}$. Considera-se que é, nesta sintonia, possível que o real objectivo da rede WWSSN em Portugal se prendesse com uma crença na "ciência pela ciência", e até que tenha havido um aproveitamento científico de um fenómeno que é na sua génese geopolítico.

Mais se desejaria acrescentar acerca da história da rede em Portugal. Do exposto nestas páginas, retira-se a escolha do IGUP como local ideal para albergar uma das 120 estações sismológicas do programa americano, os contratempos à execução da operação, o formato em que funcionou a estação e os nomes que a fizerem merecer o sucesso do qual gozou.

Itera-se que este estudo foi centrado no Instituto Geofísico da Universidade do Porto e limitado pela documentação existente, e que, por esse motivo, só ficará verdadeiramente completo quando comparado com exercícios semelhantes que tenham por objecto outras estações da rede e, sobretudo, se vier a ser possível aceder a documentação que permanece do lado americano. Mais se acrescenta que algumas ambições desta investigação não foram atendidas pelas circunstâncias actuais. O coronavírus SARS-CoV-2 fechou as portas aos arquivos indispensáveis ao ofício de historiador, e, consequentemente, fechou também as portas à possibilidade de aprofundar o impacte da nova faceta do Instituto Geofísico na comunicação social coeva, se é que algum impacte existiu. Desta feita, a esperança é a de revisitar este trabalho mais tarde com a intenção de o terminar realmente e de apresentar uma narrativa mais plena.

Por último, sublinha-se que o Instituto Geofísico da Universidade do Porto continua em actividade, como espaço complementar do ensino científico universitário, casa de uma estação climatológica secular, posto de investigação e museu temático de Ciência. No seu recinto permanece o bunker com a estação sismológica criada no âmbito da World-Wide Standard Seismograph Network. Resta aconselhar a visita para testemunhar em primeira mão este monumento da história da ciência nacional e esperar que mais explanações surjam, pois a pluralidade de olhares críticos não pode ser senão uma mais valia.

\footnotetext{
${ }^{61}$ GAGO [et al.] - op. cit., p. 491.
} 


\section{Fontes}

Arquivo do Instituto Geofísico da Universidade do Porto, documentos administrativos que compreendem o intervalo temporal de 1960 a 1965.

\section{Bibliografia}

BARTH, Kai-Henrik - “The Politics of Seismology: Nuclear Testing, Arms Control, and the Transformation of a Discipline”. Social Studies of Science. [Em Linha] Canadá: Queen’s University. Vol. 33, $\mathrm{n}^{\mathrm{o}} 5$ (2003), pp. 743-781. Disponível em WWW: $<$ URL: $<$ https://www.jstor.org/stable/3183067>.

BRAGA, Carlos Coutinho - Instituto Geofísico: Esboço Histórico. Porto: Faculdade de Ciências da Universidade do Porto, 1969.

GADDIS, John Lewis - A Guerra Fria. Lisboa: Edições 70, 2007.

GAGO, José Mariano [et al.] - "A Ciência e a Defesa em Portugal - Elementos para uma agenda de estudos futuros". In BARATA, Manuel Themudo; TEIXEIRA, Nuno Severiano (dir.) - Nova História Militar de Portugal. Lisboa: Círculo de Leitores, 2004. Vol. 5, pp. 481-533.

HOBSBAWM, Eric - Age of Extremes: The Short Twentieth Century, 1914-1991. Londres: Abacus, 1995.

MACHADO, Álvaro R. - Observatório da Serra do Pilar: breves notas históricas, estado actual, desenvolvimento. Porto: Publicações do Observatório da Serra do Pilar, 1929.

MONTEIRO, Marisa L.; SOARES, Miguel F. O. - "Meteorological (and other) Instruments Revealed: The Collection of the Geophysical Institute of Porto University". Bulletin of the Scientific Instrument Society. Londres: Scientific Instrument Society. No 104 (2010), pp. 17-21.

PETERSON, Jon; HUTT, C. R. - World-Wide Standardized Seismograph Network: A Data Users Guide. Virgínia, Estados Unidos da América: United States Geological Survey, 2014, Open-File Report 2014-1218.

SANT'OVAIA, Helena; MOURA, Rui - "Instituto Geofísico da Universidade do Porto: Passado e Futuro". Geocore: Revista do Núcleo de Geologia do Porto. Porto: Faculdade de Ciências da Universidade do Porto. No 2 (2017), pp. 10-12. 
SANTOS, Augusto Silva Lima Gomes dos - O arquivo do Instituto Geofísico (Observatório Meteorológico da Serra do Pilar) da Universidade do Porto—um estudo sistémico. [Em Linha] Porto: Universidade do Porto, 2020. Relatório de Estágio. [Consult. 18 Maio 2021]. Disponível em WWW: $<$ URL:https://repositorio-aberto.up.pt/handle/10216/130760>.

TEIXEIRA, Nuno Severiano - "Portugal e a Guerra Fria", in BARATA, Manuel Themudo; TEIXEIRA, Nuno Severiano (dir.) - Nova História Militar de Portugal. Lisboa: Círculo de Leitores, 2004. Vol. 4, pp. 56-67.

TELO, António José - “Os Anos da NATO (1946-1959)”, in BARATA, Manuel Themudo; TEIXEIRA, Nuno Severiano (dir.) - Nova História Militar de Portugal. Lisboa: Círculo de Leitores, 2004. Vol. 4, pp. 435-462. 